J. Lake Sci. (湖泊科学), 2013, 25(3):335-341

http: //www. jlakes.org. E-mail: jlakes@niglas.ac.cn

(C) 2013 by Journal of Lake Sciences

\title{
城市化对水系结构及其连通性的影响——以秦淮河中、下游为例"
}

\author{
韩龙飞, 许有鹏, 邵玉龙, 石 怡 \\ (南京大学地理与海洋科学学院,南京 210093)
}

\begin{abstract}
摘 要: 针对当前城市化所引起水系衰减、河流连通受阻以及由此所引起洪涝与水环境的问题, 以秦淮河中、下游为例, 选取 1979 和 2006 年两期流域遥感影像,分析了城市化影响下的下垫面变化特征; 选取 1980s 和 2009 年的地形图对河流 水系进行提取,借鉴景观生态学中河流廊道空间结构分析方法,通过不同时期水系分级,探讨了城市化对水系结构及其 连通性的影响. 结果表明: (1) 城市化使得 2006 年城镇用地面积相比 1979 年增加 $84.54 \mathrm{~km}^{2}$, 增加了 9 倍多, 大量林草 地、耕地以及水域转变成城镇用地; (2) 河流长度在过去的 30 年里减少了 $41 \%$, 河道主干化趋势明显; 河流发育呈现由 多元到单一、由复杂到简单的趋势; (3) 连通性参数连接率、实际结合度分别由原来的 $1.28 、 0.43$ 下降到 $0.79 、 0.26$, 河流 的连通性呈下降趋势. 该研究将为城市化地区河流水系保护提供支持与参考.
\end{abstract}

关键词: 水系结构; 连通性;城市化;秦淮河

\section{Effect of urbanization on the stream structure and connectivity - A case study in the mid- lower reaches of the Qinhuai River}

\section{HAN Longfei, XU Youpeng, SHAO Yulong \& SHI Yi}

(School of Geographic and Oceanographic Science, Nanjing University, Nanjing 210093, P. R. China)

Abstract: The effect of urbanization on the stream structure and connectivity has been a hot topic nowadays. At the present, fast urbanization has caused many enviromental problems, such as the decreasing of river numbers, rivers unconnected, water quality worsening, and frequent flood. The Qinhuai River watershed, mainly located in Nanjing City, Jiangsu Province, China, could serve as a good example. Two remote sensing images in 1979 and 2006 in mid-lower reaches of the Qinhuai River were processed and classified for the analyses on the spatial and temporal characteristics of underlying lands, which were the result of urbanization. The river systems were extracted based on the topographic maps in 1980s and 2009, and the influence on the stream structure and connectivity was discussed using a combination of stream grading and structure analysis methods on the river corridor in landscape ecology. Results show that: (1) Urban land has increased 9 times by $84.54 \mathrm{~km}^{2}$, and a large area of forest land has been transformed into urban land. Besides, paddy and dry land area were also decreased. Expanding of the urban areas of the city has invaded many other lands. (2) Length of the river has been decreased by $41 \%$ and the main river channel of the catchment are broadening. The stability of river has been declining and composition of the river system network was getting simpler. The stream stucture was developing from a complex model to a simple one. (3) Parameters of the river connectivity were both decreased. This explains why the rivers were not as well connected as 30 years ago and flood risk of this area current is high.

Keywords: Stream structure; connectivity; urbanization; Qinhuai River

城市化的发展导致流域下垫面性质发生相应的变化. 尤其在长三角地区, 经过近三十年城市化发展, 城 市不透水面积剧增, 大量河流水系遭到破坏, 河流连通能力变差 ${ }^{[1]}$, 导致城市化地区暴雨洪水过程中汇流时 间缩短、洪峰增加、径流系数增大, 加之河网的调蓄能力下降, 致使大多城市汛期” 逢雨必涝”. 城市化引起的 洪涝灾害与水环境恶化等问题,已严重威胁到人类的生存和区域经济的发展. 探讨城市化对下垫面、水系结 构及其连通性影响的特点与机制, 是社会实现可持续发展的迫切需要.

* 国家自然科学基金重点项目 (40730635) 和水利部公益性行业科研专项经费项目(201201072)联合资助. $2012-08-13$ 收稿;2012-11-20 收修改稿. 韩龙飞,男,1988 年生, 硕士研究生; E-mail : hanlongfei1988@ gmail. com. 
城市化使河道结构简化, 低等级河流不断减少. 目前国内已有一些关于城市化对河网特征的影响研究,

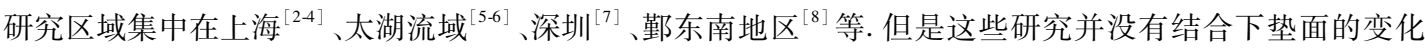
进行分析, 并且在河流连通方面很少涉及. 仅有的关于连通的文献也主要侧重于内涵、意义方面的探讨 ${ }^{[9-12]}$. 因此, 本文以秦淮河中、下游为例, 对城市化背景下的下垫面及水系特征变化进行分析, 并借鉴景观生态学 中河流廊道空间结构分析方法, 对研究区河流连通性进行初步探讨. 近些年秦淮河中、下游城市化发展加 快, 研究区较为典型, 该研究可为改善该区域水系结构及其连通性和实现水环境的可持续利用提供参考.

\section{1 研究区概况}

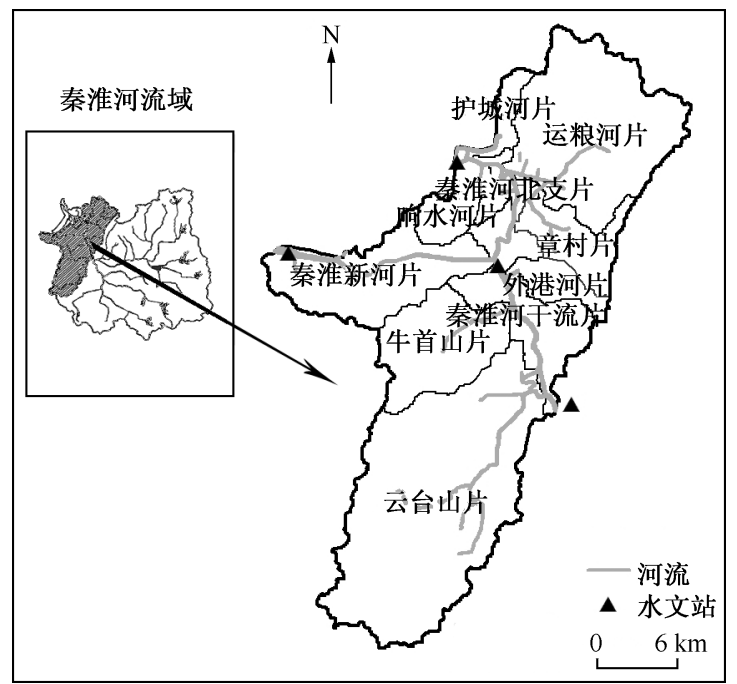

图 1 研究区示意图

Fig. 1 Location of the study area

秦淮河流域大部分位于江苏省南京市境内, 属于亚热带季风气候, 降水充沛, 年平均降雨量 $1047.8 \mathrm{~mm}$. 四面环山, 中间低平, 为典型山间盆 地, 低山丘陵面积约占 $74.3 \%$, 平原面积约占 $25.7 \%$. 地势由东南向西北倾斜. 研究区位于秦淮 河的中、下游(图 1), 面积为 $497.08 \mathrm{~km}^{2}$. 该区近 30 年经历了一个快速城市化阶段,2000 年流域人 口城市化水平已达 $59.3 \%$. 城市化的快速发展， 在促进经济快速发展的同时也带来一系列的环境 问题. 河网水系数量锐减, 河流连通性骤降, 引发 河流水质恶化, 河中生物多样性减弱, 河网调蓄能 力降低, 流域洪涝风险加大等一系列水文、水资源 与水环境问题.

秦淮河中、下游干支流纵横交错, 根据各支流 的汇水范围, 参考流域的河流地貌状况, 并结合 《南京市水资源综合规划》,把研究区分为 10 个 水利分区. 根据城市土地扩展强度指数, 10 个水 利分区分为高度城市化区、中度城市化区与低度 城市化区. 另从中选取下垫面变化较大的面积为 $117.75 \mathrm{~km}^{2}$ 的平原区来探讨其连通性变化.

\section{2 研究方法与数据基础}

选取河网密度、水面率 ${ }^{[2]}$ 及河网复杂度 $(C R)$ 和河网结构稳定度 $(S R)^{[3]}$ 来表示水系结构特征, 并选取连 接率 $(\beta)$ 和实际结合度 $(\gamma)$ 指数来分析流域连通性变化.

\section{1 水系结构参数}

河网密度, 即单位流域面积上的河流长度, 本文用研究区中河流总长与研究区面积之比得到. 水面率, 指河道 (湖泊) 多年平均水位上的水面积与区域总面积之比. CR 用于描述河网数量和长度的发育程度, 其数 值越大, 说明该区域河网的构成层次越丰富. $S R$ 用河网长度和河道面积的比值来表示, 长度和面积的不同步 演变是由河网结构变化引起的,选取此指标可定量描述一段时段内河网结构的稳定程度.

$$
\begin{gathered}
C R=N_{\mathrm{c}}\left(L / L_{\mathrm{m}}\right) \\
S R_{t}=\left(L_{t} / R A_{t}\right) /\left(L_{t-n} / R A_{t-n}\right) \quad n>0, t>n
\end{gathered}
$$

式中, $N_{\mathrm{c}}$ 为河网等级数; $L$ 和 $L_{\mathrm{m}}$ 分别代表河流总长度和河网主干河长; $S R_{t}$ 表示第 $t$ 年时, 河网在过去 $n$ 年时 间内的稳定程度; $L_{t} 、 R A_{t}$ 和 $L_{t-n} 、 R A_{t-n}$ 分别代表第 $t$ 年和第 $t-n$ 年研究区河流总长度、河道总面积. $S R$ 值大 于 1 表示河流长度发育大于面积发育, 反之则表示河流面积发育强于长度发育.

\section{2 连通性参数}

景观生态学中, 河流廊道是重要的生态廊道之一. 在河流廊道空间结构特征的度量分析指标中, 河流廊 
道连通性对于河流水文调节、生物多样性保护等生态系统服务功能有重大意义, 景观斑块之间的水文连通 是生态系统结构中重要的驱动因素 ${ }^{[13-16]}$. 本文借鉴景观生态学中河流廊道连通性的分析方法, 选取 $\beta$ 和 $\gamma$ 指数来计算和评价研究区河流结构的连通性 ${ }^{[17-18]}$ :

$$
\begin{array}{ll}
\beta=L_{\mathrm{c}} / N & 0<\beta<3 \\
\gamma=L_{\mathrm{c}} /[3(N-2)] & 0 \leqslant \gamma \leqslant 1
\end{array}
$$

式中, $L_{\mathrm{c}}$ 指河网中的河链数, $N$ 指河网节点数. $\beta$ 在景观生态学中是用来表示网络结构中廊道与节点间通达 程度, 这里用于表示河网的通达度. $\gamma$ 指数在景观生态学中是用来度量廊道在空间上的连续程度, 用网络中 实际的河链数与最大可能连接河链数之比得到, 以便描述河网各结点被连接的程度. 本文选取秦淮河中游 平原区, 利用 ArcGIS 软件对水系的河链与节点进行提取, 从而得到不同时期的 $\beta$ 、 $\gamma$ 值, 以此分析研究区水系 连通性的变化.

\section{3 数据资料}

在分析研究区土地利用变化中,本研究利用遥感影像进行下垫面特征的信息提取. 选取 1979、2006 年 2 个时段具有代表性的 Landsat TM 影像 14 景,包括 1979 年 7 景和 2006 年 7 景,遥感影像的空间分辨率均为 $30 \mathrm{~m}$. 遥感影像经过辐射校正、几何校正、直方图匹配、图像拼接和裁切及图像滤波和增强等一系列预处理 工作, 综合多种遥感图像分类算法,结合研究区的地物类型及影像光谱差异的特点和对研究区实地的考察 分析,将土地类别分为旱地、城镇用地、水田、水域和林草地 5 大类别进行影像的解译.

在对水系结构的分析中,数据源为南京市 1980s 1:50000 纸质地形图、2009 年 1:50000 电子地形图和部 分遥感影像. 平原地区河网密布, 河道纵横, 分级难度大, 为此本文根据河流宽度进行分级, 即河流宽度大于 $20 \mathrm{~m}$ 河道定为 1 级、 $10 \sim 20 \mathrm{~m}$ 为 2 级、 $10 \mathrm{~m}$ 以下为 3 级. 在数字化中, 1 级河道、湖泊、池塘作为面状地物, 其 它河道作为线状地物来处理, 提取 2 期地图水系要素, 得到 1980s 和 2009 年水系图 (图 2). 河道的面积由面 状河流与线状河流面积构成, 线状河流面积由其长度乘以其宽度得到, 其中 $2 、 3$ 级河道的宽度分别取其平 均值 15 和 $5 \mathrm{~m}$.

\section{3 结果与分析}

\section{1 土地利用时空变化}

随着城市的扩张以及江宁区经济的发展, 研究区下垫面的土地利用发生了较大的变化,较大面积的林 草地转化成城镇用地 (图 3). 1979 年林草地的面积达到 $242.26 \mathrm{~km}^{2}$, 经过将近 30 年的城市化发展, 林草地 面积锐减, 到 2006 年仅为 $108.85 \mathrm{~km}^{2}$, 面积减少 $133.41 \mathrm{~km}^{2}$, 减少近 $55.07 \%$. 除林草地外, 水田和旱地面积 存在不同幅度的减少. 水田、旱地面积在 1979 年分别为 $101.74 、 124.17 \mathrm{~km}^{2}$, 到 2006 年分别减少到 77.86 、 $111.91 \mathrm{~km}^{2}$, 减少了 $23.47 \%$ 、 $9.87 \%$. 水域面积也存在一定幅度的减少. 而城镇用地面积则呈剧增的趋势, 1979 年流域的城镇面积只有 $17.2 \mathrm{~km}^{2}$, 到 2006 年城镇用地剧增到 $101.74 \mathrm{~km}^{2}$, 相比于 1979 年增加了 9 倍 多. 林草地、水田、旱地以及水域面积均在减少, 城镇用地面积却大幅度增加. 可以看出, 30 年的城市化发展 侵占了大量林草地、耕地以及水域,这也是城市扩张的必然结果.

\section{2 水系结构及连通性变化}

\section{2 .1 水系结构变化 计算各水系参数, 得到研究区 $1980 \mathrm{~s}$ 和 2009 年的水系结构特征:}

1) 河网密度下降,河道主干化. 随着城市化的发展, 从 1980s 到 2009 年, 大部分水系指标呈显著下降趋 势. 流域内河流长度缩短了 $345.9 \mathrm{~km}$, 河网密度减少了 $41.18 \%$ (表 1 ). 随着城市的扩张, 人为进行填埋河 道, 使得河流的密度变疏. 城市化程度越高, 河流长度缩减的趋势越明显. 河流长度的减少与流域内低等级 河流的大量消失有关. 水体面积增加了 $32.28 \mathrm{~km}^{2}$, 相应地水面率增加 $17.87 \%$ (表 1). 水面率的增加与郊区 鱼塘大量开挖以及主干河流河面拓宽有关.

从 $1980 \mathrm{~s}$ 到 2009 年, 1 级河流长度缩减了 $58.9 \%$, 面积缩小了 $20.5 \%$; 级河流长度减少 $23.36 \mathrm{~km}$, 面 积减少 $0.35 \mathrm{~km}^{2}$; 级河流长度减少了 $171.46 \mathrm{~km}$ (表 2). 可以看出, 低等级河流受城市化影响明显, 长度大 量减少; 高等级河流长度与面积也均减少, 但面积减少的幅度少于长度,这主要由近 20 年人工渠道、闸、坝、 
面状水系
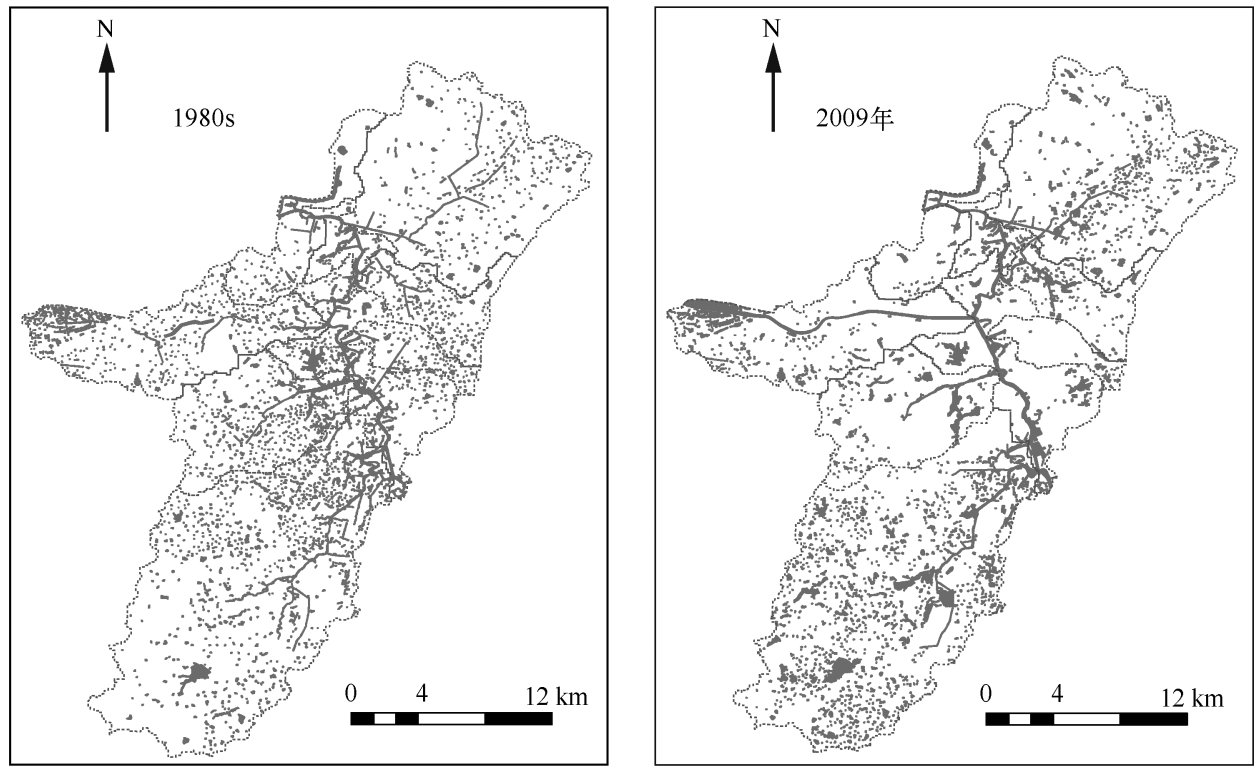

线状水系
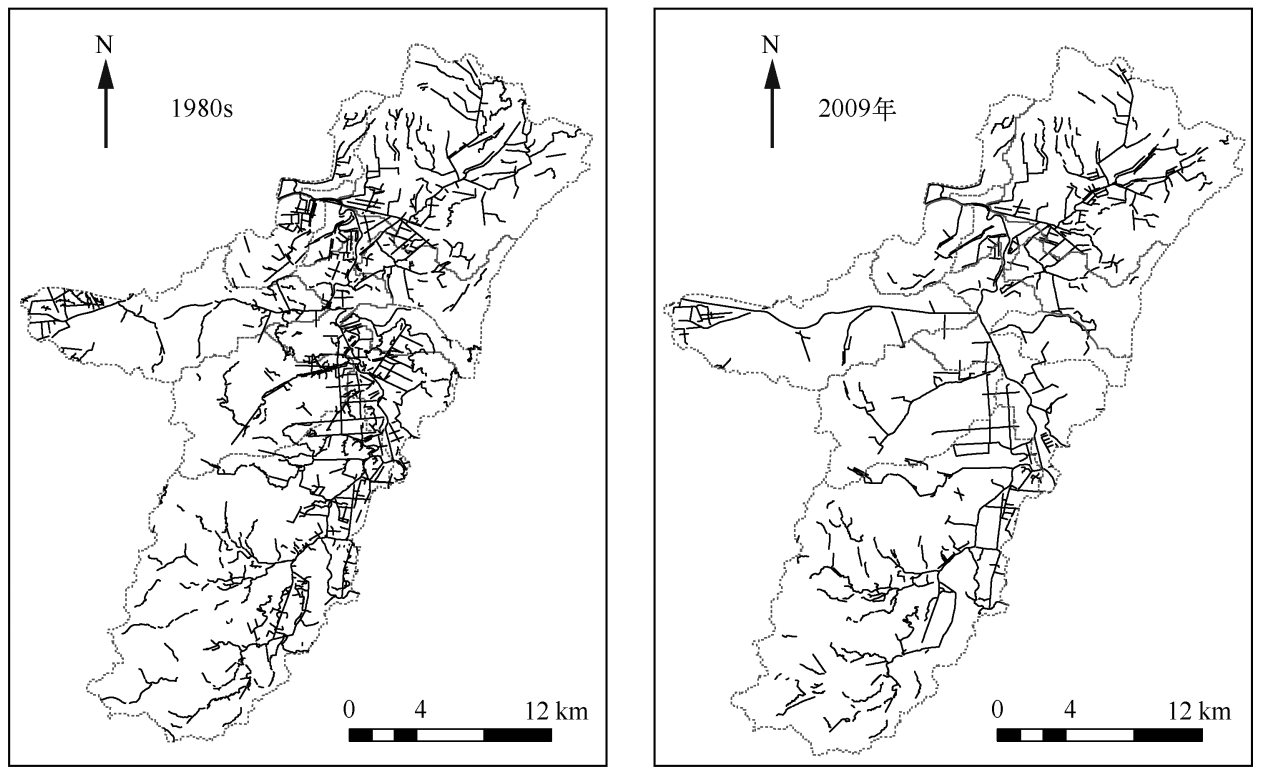

图 2 1980s 和 2009 年研究区水系

Fig. 2 Stream systems of study area in 1980s and 2009

堤防等水利工程建设所造成的, 以秦淮河干流为例, 1980s 河宽仅 $90 \mathrm{~m}, 2009$ 年已达到 $150 \mathrm{~m}$. 对于主干河流 以下的同等级河流而言,城市化水平越高, 河流的长度与面积减少得越多;对于不同等级河流, 等级越低, 受 城市化影响越显著,高等级河流受城市化影响较小.

2 ) 河网稳定程度减弱. 不同等级河流长度和面积的变化表现出不同步的状况, 3 级河流宽度较窄, 长度 与面积变化呈现出同步的状况; 1 级河流由于河流主干化,面积发育强于长度 (表 2). 秦淮河总体的 $S R$ 值低 于 1 , 说明秦淮河河流长度的减少先于河道面积的减少,河流水系的稳定度在减弱. 从水利片来看 (表 3 ), 低 

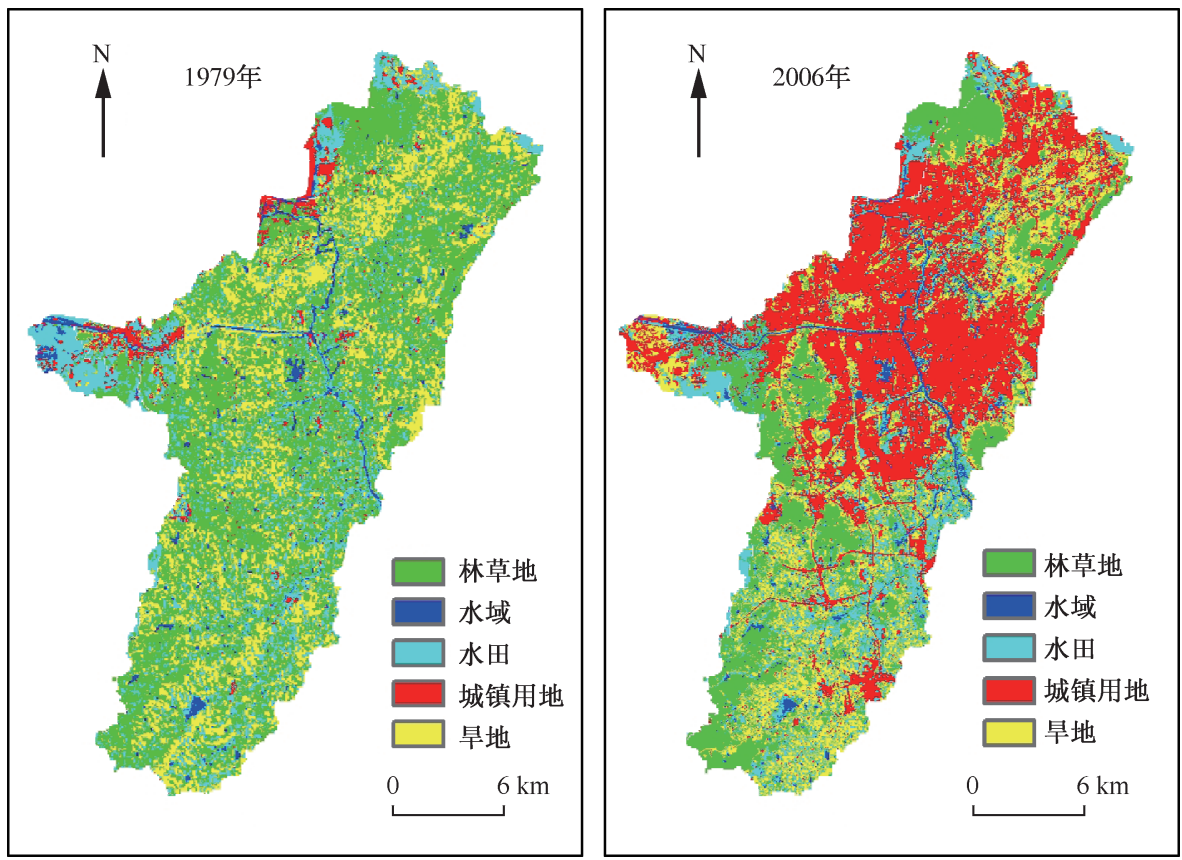

图 3 秦淮河中、下游 1979 和 2006 年土地利用/覆盖状况

Fig. 3 Land-use and coverage change in the mid-lower reaches of Qinhuai River in 1979 and 2006

度城市化区的稳定度是最高的, 稳定度达 到 0.95 ,该区河流长度与面积的发育符合 自然发展规律,受人类活动影响较小. 而对 于中度和高度城市化区, 河流的稳定度值 就低很多,如秦淮河干流片、秦淮新河片稳 定度值只有 $0.45 、 0.43$. 总的来说, 受城市 化影响发育的由主干河道所支撑的河网结 构稳定度在减弱.

3 ) 河网结构简化. 从总区域上来看 (表 3 ) , CR 在 $1980 \mathrm{~s}$ 年为 18.50 , 到 2009 年 下降到了 14.11 ,下降了 $23.72 \%$, 河网复 杂度下降,结构简化. 各个水利片的河网复 杂度均呈下降的趋势，下降的幅度在空间 上表现出不均衡性. 下降最快的是高度城 市化区的外港河片，下降幅度达 62.10\%； 中度城市化区的章村片、秦淮河干流片、 秦淮河北支片，低度城市化区的云台山 片，下降幅度均超过 $40 \%$ 。总的看来，城市 化水平越高, 河网复杂度下降越明显. 高 度城市化区河网复杂度下降最快,下降达 $50 \%$ 下降也都超过 $25 \%$. 城市化的影响下, 河网主干化趋势明显, 支撑主干河道的支流水系越发薄弱, 河网的 数量及长度的发育呈现弱化趋势, 构成层次越发简化, 河网水系发育呈现出由多元到单一、由复杂到简单 的变化趋势.

表 1 1980s 和 2009 年河网密度、水面率

Tab. 1 River density and water area rate in 1980s and 2009

\begin{tabular}{lccr}
\hline 水系结构 & $1980 \mathrm{~s}$ & 2009 年 & 变化率 \\
\hline 河网密度 $/\left(\mathrm{km} / \mathrm{km}^{2}\right)$ & 1.70 & 1.00 & $-41.18 \%$ \\
水面率 $/\left(\mathrm{km}^{2} / \mathrm{km}^{2}\right)$ & 6.38 & 7.52 & $17.87 \%$ \\
\hline
\end{tabular}

表 2 1980s 和 2009 年流域不同等级河流变化 Tab. 2 Changes of length and area of different grade rivers in 1980 s and 2009

\begin{tabular}{lcccc}
\hline 河流变化 & 时期 & 1 级河流 & 2 级河流 & 3 级河流 \\
\hline 长度 $/ \mathrm{km}$ & $1980 \mathrm{~s}$ & 256.73 & 303.61 & 282.61 \\
& 2009 年 & 105.64 & 280.25 & 111.15 \\
变化率 & & $-58.9 \%$ & $-7.7 \%$ & $-60.7 \%$ \\
\hline 面积 $/ \mathrm{km}^{2}$ & $1980 \mathrm{~s}$ & 9.74 & 4.55 & 2.26 \\
& 2009 年 & 7.74 & 4.20 & 0.89 \\
变化率 & & $-20.5 \%$ & $-7.7 \%$ & $-60.6 \%$ \\
\hline
\end{tabular}

, 绝大部分中度城市化区和低度城市化区的水利片复杂度 西 
表 3 研究区不同水利片 1980 s 和 2009 年水系结构参数

Tab. 3 Parameters of river system structure in different zones of study area in 1980s and 2009

\begin{tabular}{|c|c|c|c|c|c|c|c|c|c|c|c|c|c|c|}
\hline \multirow[b]{2}{*}{ 水系结构参数 } & \multicolumn{3}{|c|}{ 高度城市化区 } & \multicolumn{7}{|c|}{ 中度城市化区 } & \multicolumn{3}{|c|}{ 低度城市化区 } & \multirow[b]{2}{*}{ 总区域 } \\
\hline & $\begin{array}{l}\text { 外港 } \\
\text { 河片 }\end{array}$ & $\begin{array}{l}\text { 响水 } \\
\text { 河片 }\end{array}$ & $\begin{array}{c}\text { 平均 } \\
\text { 值 }\end{array}$ & $\begin{array}{c}\text { 北支 } \\
\text { 片 }\end{array}$ & $\begin{array}{c}\text { 干流 } \\
\text { 片 }\end{array}$ & $\begin{array}{c}\text { 章村 } \\
\text { 片 }\end{array}$ & $\begin{array}{l}\text { 牛首 } \\
\text { 山片 }\end{array}$ & $\begin{array}{l}\text { 运粮 } \\
\text { 河片 }\end{array}$ & $\begin{array}{c}\text { 新河 } \\
\text { 片 }\end{array}$ & $\begin{array}{c}\text { 平均 } \\
\text { 值 }\end{array}$ & $\begin{array}{l}\text { 护城 } \\
\text { 河片 }\end{array}$ & $\begin{array}{l}\text { 云台 } \\
\text { 山片 }\end{array}$ & $\begin{array}{c}\text { 平均 } \\
\text { 值 }\end{array}$ & \\
\hline 土地扩展指数 ${ }^{1)}$ & 2.98 & 2.67 & 2.83 & 2.15 & 2. 10 & 2.01 & 1.55 & 1.42 & 1.36 & 1.77 & 0.66 & 0.46 & 0.56 & 1.74 \\
\hline$S R$ & 0.74 & 1.26 & 0.96 & 0.75 & 0.45 & 0.93 & 0.78 & 0.98 & 0.43 & 0.67 & 0.92 & 0.94 & 0.95 & 0.76 \\
\hline CR $\quad 1980 \mathrm{~s}$ & 47.06 & 31.92 & 38.10 & 10.72 & 11.91 & 16.46 & 10.82 & 41.40 & 13.50 & 15.30 & 6.96 & 33.29 & 26.51 & 18.50 \\
\hline 2009 年 & 17.82 & 30.52 & 19.10 & 5.53 & 5.82 & 6.35 & 10.53 & 30.78 & 7.41 & 13.10 & 5.10 & 17.3 & 15.12 & 14.11 \\
\hline 变化率/\% & -62.10 & -4.36 & -50.00 & -48.43 & $-51.13-$ & -61.40 & $-2.70-$ & -25.70 & $-45.07-$ & $-15.00-$ & 26.76 & -48.03 & -42.95 & -23.72 \\
\hline
\end{tabular}

1) 土地扩展指数, 即城市土地扩展强度, 指空间单元在研究时期内的城市土地扩展面积占其土地总面积的百分比.

表 4 不同时期研究区连通各参数

Tab. 4 Parameters of river connectivity in study area in 1980s and 2009

\begin{tabular}{ccccccc}
\hline 时期 & 河链数 & 节点数 & $\begin{array}{c}\text { 河链密度/ } \\
\left(\mathrm{km} / \mathrm{km}^{2}\right)\end{array}$ & $\begin{array}{c}\text { 河链平均 } \\
\text { 长度 } / \mathrm{km}\end{array}$ & $\beta$ & $\gamma$ \\
\hline $1980 \mathrm{~s}$ & 915 & 713 & 7.77 & 0.27 & 1.28 & 0.43 \\
2009 年 & 97 & 123 & 0.82 & 1.05 & 0.79 & 0.26 \\
\hline
\end{tabular}

3.2 .2 水系连通性变化 研究区河链和节 点数均大幅减少, 河链数在 $1980 \mathrm{~s}$ 达 915 条, 到 2009 年减少到不足 97 , 减少率高达 $89.4 \%$; 节点数也由 $1980 \mathrm{~s}$ 的 713 个减少到 2009 年的 123 个 (表 4). 城市扩张, 大量支 流小河道被填埋消失, 这些低等级河流的 消亡在地图上表现为河链数的减少, 同时 引起节点数的减少. 相应地, 河链密度由 $1980 \mathrm{~s}$ 年的 7.77 下降到 2009 年的 0.82 . 这

与 3.2.1 中提到河网密度减少相一致. 而河链平均长度却呈现出增加的趋势, 这与河流主干化密切相关. 低 等级河流大量消亡, 高等级河流却不断进行拓宽维护, 使得这一数值由原来的 0.27 上升到 2009 年的 1.05 . 由此可见,这些指标也同时反映了河流结构的变化情况.

城市化对河流水系的连通性影响显著, 廊道的连接率明显下降, 由 1980s 的 1.28 下降到 2009 年的 0.79 , 说明廊道与各节点之间的通达能力在减弱, 河道之间不再畅通. 同时, 实际结合度也同样呈现下降的 趋势, $1980 \mathrm{~s}$ 为 $0.43,2009$ 年则下降到 0.26 , 河流之间空间上的连续程度在下降. 随着城市的扩张, 原来的一 些小河道被填埋变成城镇用地, 小河道逐渐消失, 大河道与小河道之间不再连通. 原来纵横交错的河网连通 性变差, 以城市化为代表的人类活动影响了河流水系结构及连通性, 使得河系的连通性降低. 河流连通性的 下降使得流域洪灾风险加大,严重制约着社会经济的发展.

\section{4 结论与展望}

1) 由土地利用分析得出,城市化对流域的土地利用/覆被变化影响显著. 城镇用地面积剧增, 大量非城 镇用地变成城镇用地, 南京江宁区的城市扩张以占用林草地、耕地以及水域为主.

2 ) 低等级河流受人类活动影响较高等级河流更大, 大量低等级河流因城市化的发展而填埋、消失, 而主 干河流所受的影响主要体现在河道拓宽. 城市的发展的同时, 河网的稳定程度减弱. 空间上讲, 稳定程度与 城市化程度的高低呈负相关关系. 城市化水平越高, 河网复杂度下降越明显, 河网的构成层次越简化, 发育 呈由复杂到简单的趋势.

3) 河流连通的变化体现出结构的变化, 大量支流的消失, 引起研究区河链和节点数均大幅减少, 导致廊 道的连接率和实际结合度值亦下降 $66.4 \% 、 67.1 \%$,连通性明显降低, 流域的防洪压力加大.

由于平原水网地区, 河流流向不定, 基于图论采用景观生态学的指标, 能较好地反映平原河网的实际情 况, 具有一定的指导意义. 但在汛期, 河网连通情况还受闸门与泵站调度影响, 因此具有一定的局限性. 城市化 对河流水系结构及其连通性的影响是一个复杂的过程, 从河流地貌学和景观生态学的角度, 选取一些典型指标来 表征水系结构及其连通性, 为两者之间关系定量化描述提供一些参考, 为以后深人研究打下基础. 本文的研究只是 
一个初步结果, 如何更加全面地开展平原水网地区河流水系与连通性变化规律研究, 还有待进一步探索分析.

\section{5 参考文献}

[ 1 ] 许有鹏. 长江三角洲地区城市化对流域水系与水文过程的影响. 北京:科学出版社,2012:13-35.

[2] 杨 凯,袁 雯,赵 军等. 感潮河网地区水系结构特征及城市化响应. 地理学报,2004,59(4):557-564.

[ 3 ] 袁 雯,杨 凯,徐启新. 城市化对上海河网结构和功能的发育影响. 长江流域资源与环境,2005,14(2):133-138.

[4] 程 江,杨 凯,赵 军等. 上海中心城区河流水系百年变化及影响因素分析. 地理科学, 2007,27(1):85-91.

～ 5 ] 苏伟忠,杨桂山. 太湖流域南河水系无尺度结构. 湖泊科学,2008,20(4) :514-519.

[6] 王柳艳,许有鹏, 余铭婧. 城镇化对太湖平原河网的影响一以太湖流域武澄锡虞区为例. 长江流域资源与环境, 2012,21 (2) : 151-156.

[ 7 ] 黄奕龙,王仰麟, 刘振环等. 快速城市化地区水系结构变化特征. 地理研究,2008,27(5):1212-1220.

[8] 陈云霞,许有鹏,付维军. 浙东沿海城镇化对河网水系的影响分析. 水科学进展,2007,18(1):68-73.

[9] 唐传利. 关于开展河湖连通研究有关问题的探讨. 中国水利,2011,6:86-89.

[10] 夏 军,高 扬,左其亭等. 河湖水系连通特征及其利弊. 地理科学进展, 2012,31(1):26-31.

[11］李宗礼,刘晓洁,田 英等. 南方河网地区河湖水系连通的实践与思考. 资源科学,2011,33(12):2221-2225.

[12］张欧阳,熊 文,丁洪亮. 长江流域水系连通特征及其影响因素分析. 人民长江,2010,(1):1-5.

[13 ] Junk WJ, Bayley PB, Sparks RE. The flood pulse concept in river-floodplain systems. In: Dodge DP ed. Proceedings of the International Large River Symposium. Canadian Special Publication in Fisheries and Aquatic Sciences, 1989, 106: $110-127$.

[14] Amoros C, Bornette G. Connectivity and biocomplexity in waterbodies of riverine floodplains. Freshwater Biology, 2002, $47(4): 761-776$.

[15] Pringle C. What is hydrologic connectivity and why is it ecologically important? Hydrological Processes, 2003,17 ( 13): 2685-2689.

[16] Thorp JH, Thoms MC, Delong MD. The riverine ecosystem synthesis: biocomplexity in river networks across space and time. River Research and Applications, 2006 ,22:123-147.

[17］何晓蓉,李辉霞,范建容等. 青藏高原流域廊道体系对生态环境的影响. 水土保持研究,2004,11(2):97-99.

[18］罗 坤,蔡永立, 郭纪光等. 崇明岛绿色河流廊道景观格局. 长江流域资源与环境,2009,18(10):908-913. 